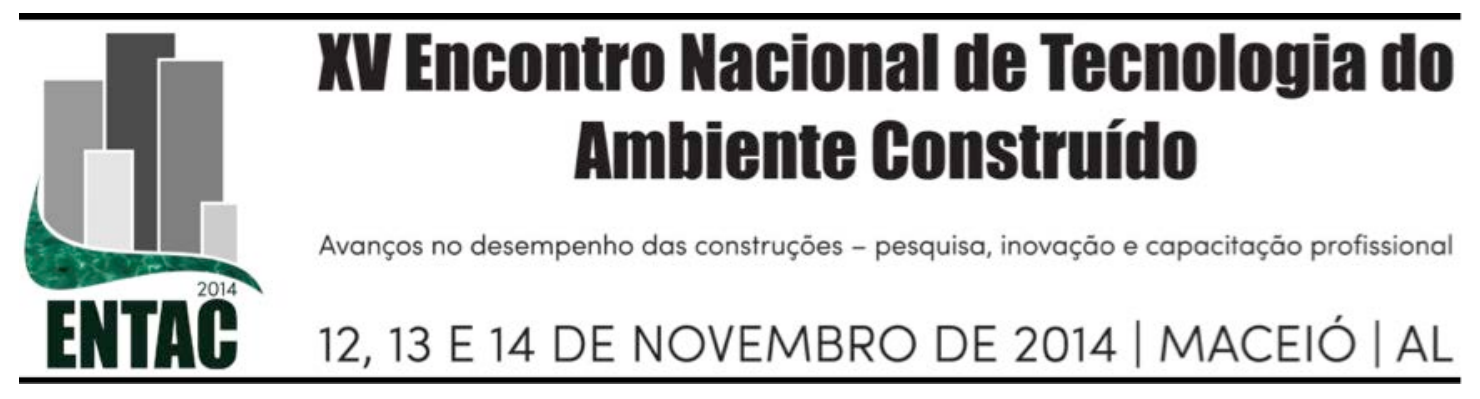

\title{
ANÁLISE DO DESEMPENHO TÉRMICO DE BLOCOS EVA E BLOCOS DE CONCRETO
}

\section{GOMES, Emmily Gérsica Santos (1); DUARTE, Juliana de Souza (2); ROBERTO, Eric (3), WOENSEL, Fernando Van (4); NÓBREGA, Larissa (5); CUNHA, Ronnie (6)}

(1)UFPB, e-mail: emmilygersica@gmail.com (2)UFPB, e-mail: duartejuliana05@gmail.com (3) UFPB, e-mail: eribeto@gmail.com (4)UFPB,e-mail:fernandovw@gmail.com (5)UFPB,e-mail: larinobrega@gmail.com; (6) UFPB,e-mail: ronnie.cunha@gmail.com

\section{RESUMO}

O declínio progressivo da disponibilidade de matéria prima para o processo de industrialização tem levado à busca de estratégias para manutenção da produção, como a reciclagem e o reaproveitamento de resíduos. A utilização dos resíduos de etileno-acetato de vinila (EVA), gerados em grandes quantidades pelas indústrias de calçados, é uma alternativa viável na produção de blocos de vedação, sem função estrutural. Este artigo apresenta uma análise do desempenho térmico de blocos EVA em comparação com blocos de concreto. A pesquisa foi desenvolvida em uma disciplina de Mestrado, que abordava o uso de materiais não convencionais na arquitetura, e se integra a uma pesquisa em andamento sobre o desempenho térmico de blocos EVA. O estudo experimental iniciou-se a partir da confecção, em laboratório, dos blocos EVA e de concreto para montagem de duas mini paredes, as quais foram subdivididas em blocos vazios e blocos preenchidos com o mesmo material do bloco, para serem submetidas a testes em uma câmara térmica de laboratório. Nesses experimentos, uma das faces da amostra foi aquecida através de uma fonte de calor e a outra foi refrigerada. O ensaio de cada amostra durou $24 \mathrm{~h}$, onde as temperaturas superficiais foram registradas por meio de termopares conectados a um sistema de aquisição (MX840A). Foram feitos os cálculos de desempenho térmico (NBR 15220-2/2005) e a partir da obtenção das médias das temperaturas por hora e da verificação da diferença entre o lado aquecido e refrigerado, foi realizada uma análise comparativa do desempenho térmico das duas mini paredes, tanto do lado preenchido quanto do lado em que os blocos mantiveram suas câmaras internas de ar. Os resultados apontaram um melhor desempenho nas amostras executada com blocos EVA. Acredita-se que o agregado de EVA presente na composição do bloco contribuiu para a melhora do isolamento térmico.

Palavras-chave: Bloco EVA, bloco de concreto, desempenho térmico.

\begin{abstract}
The progressive decline in the availability of raw materials for the industrialization process has led to the search of strategies for maintaining production, such as recycling and reuse of waste. The use of ethylene vinyl acetate (EVA) waste, generated in large quantities by the footwear industry, is a viable alternative in the production of bricks with no structural function. This article presents an analysis of the thermal performance of EVA blocks compared to concrete blocks. The research was developed during a Masters assignment, which addressed the use of unconventional materials in architecture, and integrates the ongoing research on the thermal performance of EVA blocks. The experimental study started with the preparation in the laboratory of EVA and concrete blocks for building two mini walls, which were subdivided into filled and hollow blocks, to undergo tests in a laboratory thermal chamber. In these experiments, one side of the sample was heated using a heat source and the other was refrigerated. The test lasted 24 hours for each sample, where the surface temperatures were recorded using thermocouples connected to a data acquisition system (MX840A). Calculations of thermal performance (NBR 15220-2/2005) were made and the resulting means of the hourly temperatures and the difference between the hot and cold sides resulted in a comparative thermal performance analysis of the two mini walls, which were made half with filled blocks, half with hollow blocks. The results showed a better performance in the samples built with EVA blocks. We believe that the addition of EVA in the composition of this block contributed to the improvement of thermal insulation.
\end{abstract}


Keywords: EVA block, concrete block, thermal performance.

\section{INTRODUÇÃO}

Dentro dos processos de industrialização são gerados resíduos indesejáveis cuja destinação inadequada, como o lançamento direto ao meio ambiente ou a queima indiscriminada, contribui para o agravamento de problemas ambientais. A exploração intensa de recursos naturais tem provocado um declínio progressivo na disponibilidade de matéria prima para a produção industrial. A construção civil é um dos setores da economia que mais consome recursos naturais e a escassez crescente de recursos tem encarecido a matéria prima. Impulsionado por políticas que incentivam a sustentabilidade, esse setor busca saídas para essa realidade através de novas tecnologias, materiais e sistemas construtivos.

A reciclagem e o reaproveitamento de resíduos tornaram-se estratégicos em termos de política econômica e industrial. Assim, estão sendo cada vez mais procuradas formas diversas e oportunidades de valorização de resíduos nos materiais e componentes de construção civil industrial (ROCHA e CHERIAF, 2003). As legislações ambientais tem se tornado mais rigorosas, obrigando os geradores de resíduos a tratá-los de maneira adequada, e despertado para novas políticas de minimização e reciclagem de resíduos (MELO e FILHO, 2009). Conforme Andrade e Medeiros (2012), a reutilização de resíduos evita o descarte de materiais não biodegradáveis na natureza e possibilita seu uso como matéria prima de baixo custo para diversos setores da construção civil.

De acordo com Garlet apud Melo e Filho (2009), alguns desses resíduos, como o copolímero de etileno-acetato de vinila (EVA) gerados em grandes quantidades pelas indústrias de calçados, são apenas parcialmente (cerca de 20\%) reaproveitados no próprio processo de produção, devido às limitações de suas características físicas. Segundo Garlet e Greven (1997), o EVA apresenta características importantes, como a alta elasticidade, flexibilidade, resistência mecânica, soldabilidade, elevada resistência à quebra sob tensões ambientais e também a baixas temperaturas. Estudos têm ressaltado as qualidades da utilização de resíduos de EVA na produção de concreto leve (GARLET, GREVEN, 1997), placas de concreto leve (MEDEIROS, ANDRADE, 2012) e blocos de concreto (MELO, FILHO, 2009), (FILHO, 2005). Tais estudos atestam a viabilidade do uso de resíduos de EVA e confirmam as vantagens de algumas de suas propriedades físicas para a confecção de produtos para a construção civil. De acordo com Silva, Cahino e Melo (2012), a geometria, a espessura dos blocos EVA, bem como o teor de EVA incorporado, influenciam no desempenho térmico dos componentes. Neste artigo busca-se complementar tais estudos e elevar a confiabilidade de suas aplicações.

\section{OBJETIVOS}

O objetivo deste trabalho é estudar um componente não convencional, o bloco EVA, e avaliar seu desempenho térmico em comparação de mini paredes executadas com o de um material convencional, o bloco de concreto, levando em consideração a presença e a ausência da câmara de ar não ventilada nos dois tipos de blocos.

\section{PROCEDIMENTOS METODOLÓGICOS}

Inicialmente foram produzidas mini paredes com dimensões de 1,0m x 1,0m, formadas por blocos EVA (Figura 01a) e blocos de concreto (Figura 01b) para serem utilizadas, como amostras, nos testes de desempenho térmico em câmara térmica de laboratório. 

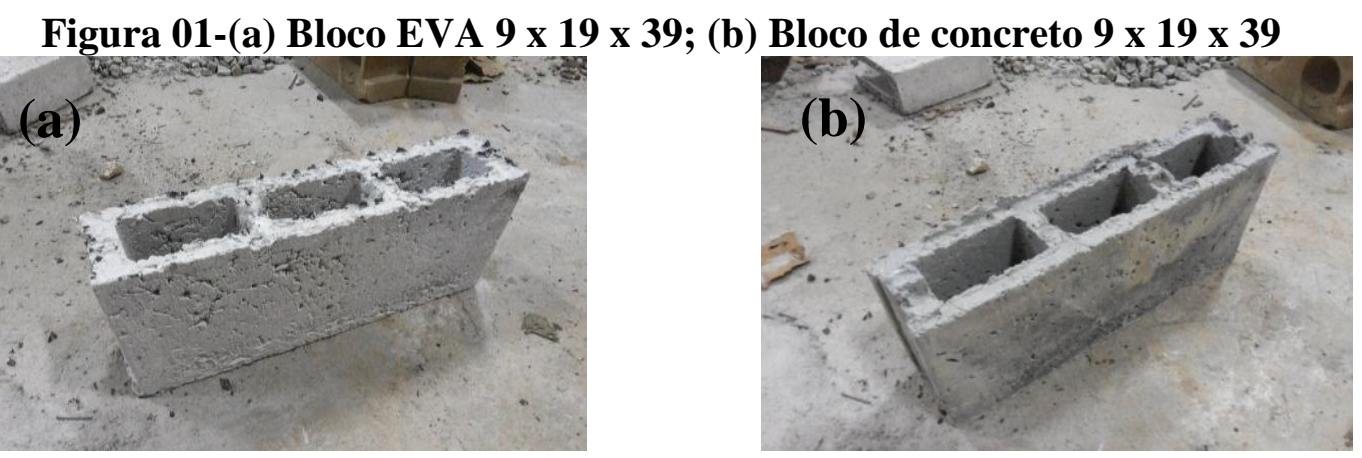

Fonte: Acervo dos autores

Os blocos EVA nas dimensões $9 \mathrm{~cm}$ x $19 \mathrm{~cm}$ x $39 \mathrm{~cm}$ foram fabricados com dosagem 1:5 (cimento: agregado, em volume) sendo a proporção entre os agregados graúdos (EVA $\mathrm{D}_{\text {máx }}=9,5 \mathrm{~mm}$ ) e miúdos (areia - $\mathrm{D}_{\text {máx }}=2,4 \mathrm{~mm}$ ) $60 \%$ e $40 \%$, relação água cimento de 0,55 (sempre utilizando o cimento Portland CP II F 32), adotando-se os controles de produção consolidados em pesquisas anteriores (DE MELO \& LIMA FILHO, 2009). Os ensaios de granulometria do EVA e da areia foram feitos segundo a norma NBR NM 248 (ABNT, 2003). Após a separação e dosagem, a mistura dos materiais seguiu as seguintes etapas: molhagem da betoneira; inserção do agregado graúdo (EVA) $+1 / 3$ de $\mathrm{H}_{2} \mathrm{O}$ (misturado por 01 minuto); acréscimo de cimento (misturado por 2 minutos); adição de $2 / 3 \mathrm{H}_{2} \mathrm{O}+$ areia (misturado por 03 minutos) e verificação da consistência da mistura moldável com o "teste da mão".

Figura 02 - Mistura do material para a moldagem dos blocos EVA

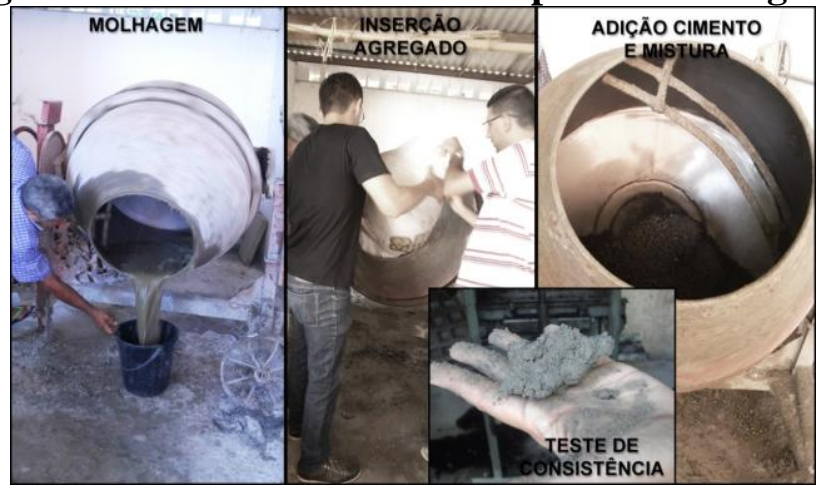

Fonte: Acervo dos autores

Os blocos de concreto, foram moldados nas mesmas dimensões que o bloco EVA (9 cm x $19 \mathrm{~cm} \mathrm{x} 39 \mathrm{~cm}$ ) e fabricados com traço 1:8,6. As etapas de mistura obedeceram os procedimentos convencionais. As moldagens dos blocos EVA e de concreto foram feitas na máquina vibro-prensa semi-automática (Figura 03a). Foram feitos 18 blocos de EVA e 18 blocos de concreto, após a moldagem, foram levados para cura em uma câmara úmida (Figura 03b), onde permaneceram por 24 horas. Em seguida foram colocados em tanques de cura com água saturada e cal (Figura 03c), e retirados para secagem 02 (dois) dias antes da execução da mini parede. Para viabilizar o ensaio de resistência à compressão, foram mantidos alguns blocos no tanque até completarem 28 dias de idade e estarem aptos para o teste. Nestes ensaios de resistência à compressão, a partir de cinco exemplares, tendo como média encontrada valores maiores do que $1,30 \mathrm{Mpa}$ para o bloco de concreto e $1,56 \mathrm{Mpa}$ para o bloco de EVA. 
Figura 03- (a) máquina vibro-prensa semi-automática; (b) câmara úmida; (c) tanques
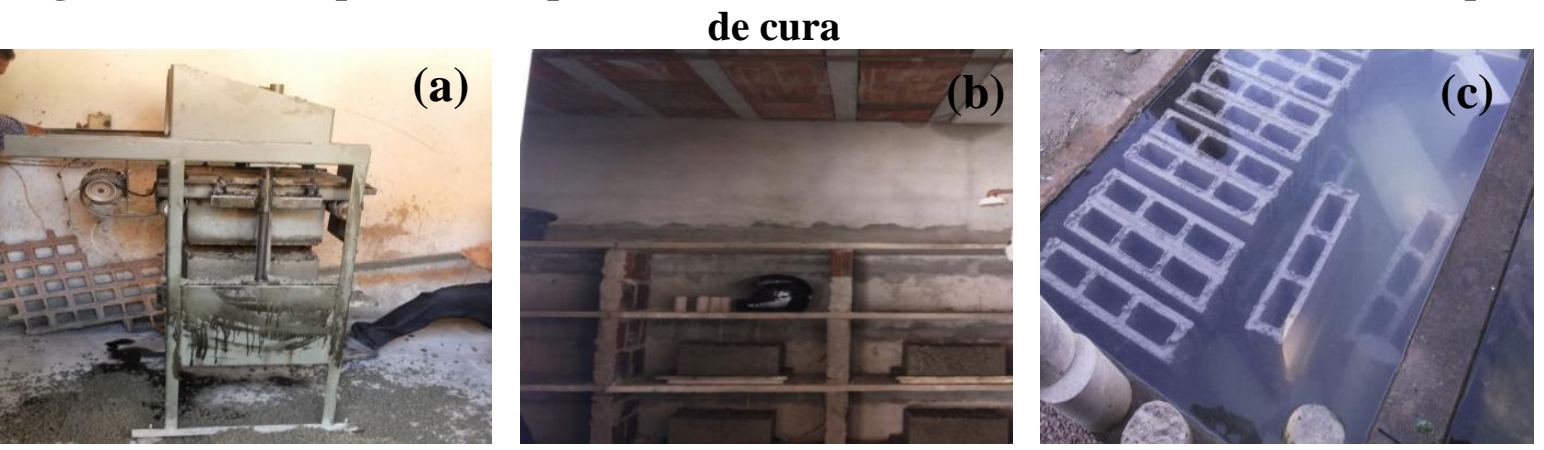

Fonte: Acervo dos autores

Após o processo de moldagem, cura e verificação da resistência à compressão dos blocos, foram construídas duas mini paredes de $1 \mathrm{~m}^{2}$ : uma mini parede de blocos EVA (Figura 04a) e outra de blocos de concreto (Figura 04b); ambas divididas ao meio por material isolante térmico (isopor). Uma das metades das mini paredes, tiveram as câmaras de ar de seus blocos preenchidas- o preenchimento foi feito com o mesmo material usado na composição de cada bloco-, enquanto a outra metade das mini paredes permaneceram com os blocos vazios. Dessa forma foi possível analisar o desempenho térmico de cada parte das mini paredes (blocos vazios, presença de câmara de ar; e blocos preenchidos)

Figura 04- (a) mini parede com blocos EVA preenchidos e vazios; (b) mini parede com blocos de concreto preenchidos e vazios
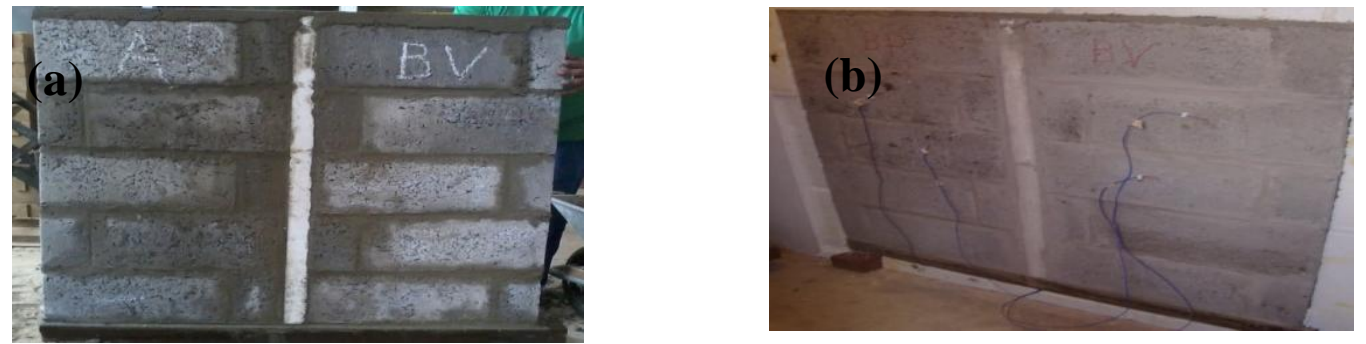

Fonte: Acervo dos autores

Adotou-se como regra realizar os ensaios somente 03 dias após a execução das mini paredes. A instrumentação foi realizada dentro de uma câmara térmica $\left(8,32 \mathrm{~m}^{2}\right)$ de forma a analisar comparativamente o desempenho térmico dos blocos EVA (vazios e os preenchidos com o mesmo material que compõe os blocos EVA) e dos blocos de Concreto (vazios e os preenchidos com mesmo material que compõe os blocos de concreto).

Figura 05- Câmara térmica: (a) lado aquecido e refrigerado da câmara térmica;

(b) divisória em gesso acartonado com espaço para mini parede (amostra)

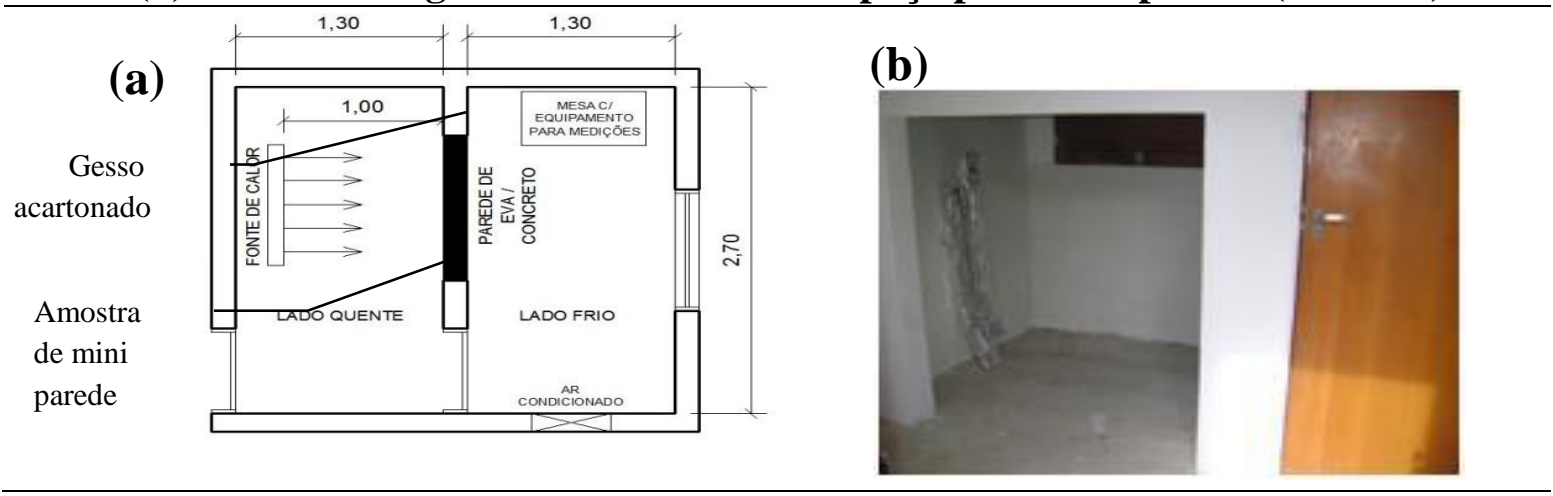


Fonte: Acervo dos autores

A câmara térmica do Laboratório de materiais e estruturas da UFPB (LABEME) (Figura 05) é subdividida em dois espaços, para que um seja aquecido e o outro refrigerado (Figura 05a). Na parede central- divisória de isolamento- feita de gesso acartonado, está o espaço para colocação da mini parede a ser avaliada (Figura 05b). A instrumentação das mini paredes foi feita através da fixação de termopares no centro geométrico de cada bloco, coincidindo sempre com a câmara de ar nas amostras de blocos vazios. Os fios foram então conectados a um sistema de aquisição de dados (MX840A da HBM) programado para registrar os valores das temperaturas a cada minuto (Figura 06).

Figura 06- Esquema da localização dos termopares nas faces das mini paredes

\begin{tabular}{|c|c|c|c|c|c|}
\hline \multicolumn{2}{|c|}{ OPOSTA } & & \multicolumn{2}{|c|}{ EXPOSTA } & \multirow[b]{3}{*}{ (b) Identificação e } \\
\hline $\mathrm{BP}$ & BV & \multirow{5}{*}{$\begin{array}{l}\text { (a) Identificação e } \\
\text { posição dos termopares } \\
\text { face "oposta" ao calor. } \\
\text { Parte com bloco } \\
\text { preenchido (BP) e bloco } \\
\text { vazio (BV) }\end{array}$} & BV & $\mathrm{BP}$ & \\
\hline & & & & & \\
\hline$\cdot 1$ & .3 & & 7. & 5 . & \multirow{4}{*}{$\begin{array}{l}\text { face "exposta" ao } \\
\text { calor. Parte com bloco } \\
\text { vazio (BV) e bloco } \\
\text { preenchido (BP) }\end{array}$} \\
\hline .2 & .4 & & 8 . & 6. & \\
\hline & & & & & \\
\hline & & & & & \\
\hline
\end{tabular}

Fonte: Acervo dos autores

O ensaio de variação de temperatura seguiu o procedimento descrito por Silva, Cahino e Melo (2012), tendo uma duração de 24 horas de medições para cada mini parede (Figura 07). A instrumentação dos corpos de prova se fez com oito termopares compostos por fio cobre (+) e constantan (-), com bainha e isolante de plástico. Estes foram distribuídos da seguinte forma: quatro termopares colocados na face exposta ao calor, e quatro termopares colocados na face oposta em posições correspondentes. Todos os termopares foram protegidos com isopor, para evitar que eventuais trocas de calor, por convecção, comprometessem os resultados.

Figura 07- Imagem com termopares instalados na mini parede com bloco de EVA (a)Face submetida a fonte de calor (b) Face oposta a fonte de calor

(a)

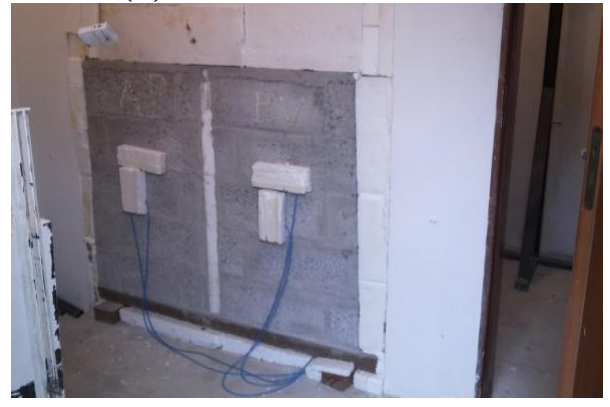

(b)

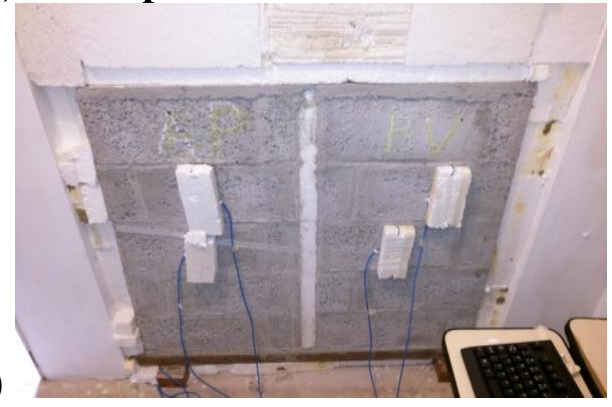

Fonte: Acervo dos autores

Nos ensaios, utilizou-se uma fonte de calor dispersa por meio de um dispositivo projetado especificamente para esse fim, composto de uma caixa metálica de dimensões $73,5 \mathrm{~cm} \mathrm{x}$ $62 \mathrm{~cm} \times 18 \mathrm{~cm}$ com uma base elevada a $0,38 \mathrm{~m}$ do piso contendo 12 lâmpadas incandescentes (150W) totalizando $1.800 \mathrm{~W}$ de potência. Esse dispositivo foi posicionado a uma distância de $1 \mathrm{~m}$ da mini parede, de forma que o calor incidisse em toda sua superfície. 
$\mathrm{Na}$ sistematização dos dados, foram consideradas as temperaturas identificadas pelos oito termopares, através das médias finais por hora para cada face das mini paredes, nas metades com blocos preenchidos e vazios. Com essas médias foram determinadas as variações médias de temperatura entre as faces exposta e oposta ao calor de cada mini parede. A temperatura média global para cada face das amostras ensaiadas foi calculada sem considerar os dados registrados nas 4 horas iniciais, levando em conta que este é um período em que as temperaturas nos termopares ainda estão tendo grande oscilação.

Para complementar a análise do desempenho dos materiais utilizados na fabricação das mini paredes e dos componentes foram realizados cálculos de desempenho térmico, segundo a norma de desempenho térmico 15220-2 (ABNT, 2005a).

\section{ANÁLISE DOS RESULTADOS}

A análise foi realizada em três etapas. Primeiramente mediu-se o desempenho da mini parede com blocos de EVA, cujos dados são apresentados a seguir. A segunda etapa traz os resultados para a mini parede de blocos de concreto. Na etapa final foi realizada uma análise comparativa entre os dois resultados.

\section{Etapa I - Desempenho térmico da mini parede com blocos de EVA}

A figura 09 apresenta o gráfico das temperaturas coletadas durante as $24 \mathrm{~h}$ de ensaio da mini parede com bloco EVA. Observou-se que na face exposta à fonte de calor, a metade da parede com blocos preenchidos apresentou uma temperatura superficial média em torno de $37^{\circ} \mathrm{C}$, enquanto que a metade da parede composta por blocos vazios apresentou temperatura em torno de $38^{\circ} \mathrm{C}$.

$\mathrm{Na}$ face oposta à fonte de calor (lado resfriado), a metade da parede com blocos vazios registrou uma temperatura média de $27^{\circ} \mathrm{C}$ enquanto que, na parte com blocos preenchidos, as temperaturas coletadas ficaram em torno de $25^{\circ} \mathrm{C}$. Percebe-se também que somente após as quatro primeiras horas as temperaturas alcançam um patamar constante de temperatura, apresentando pequenas variações durante as horas seguintes.

Figura 09- Gráfico da temperatura nas faces da mini parede com blocos em EVA

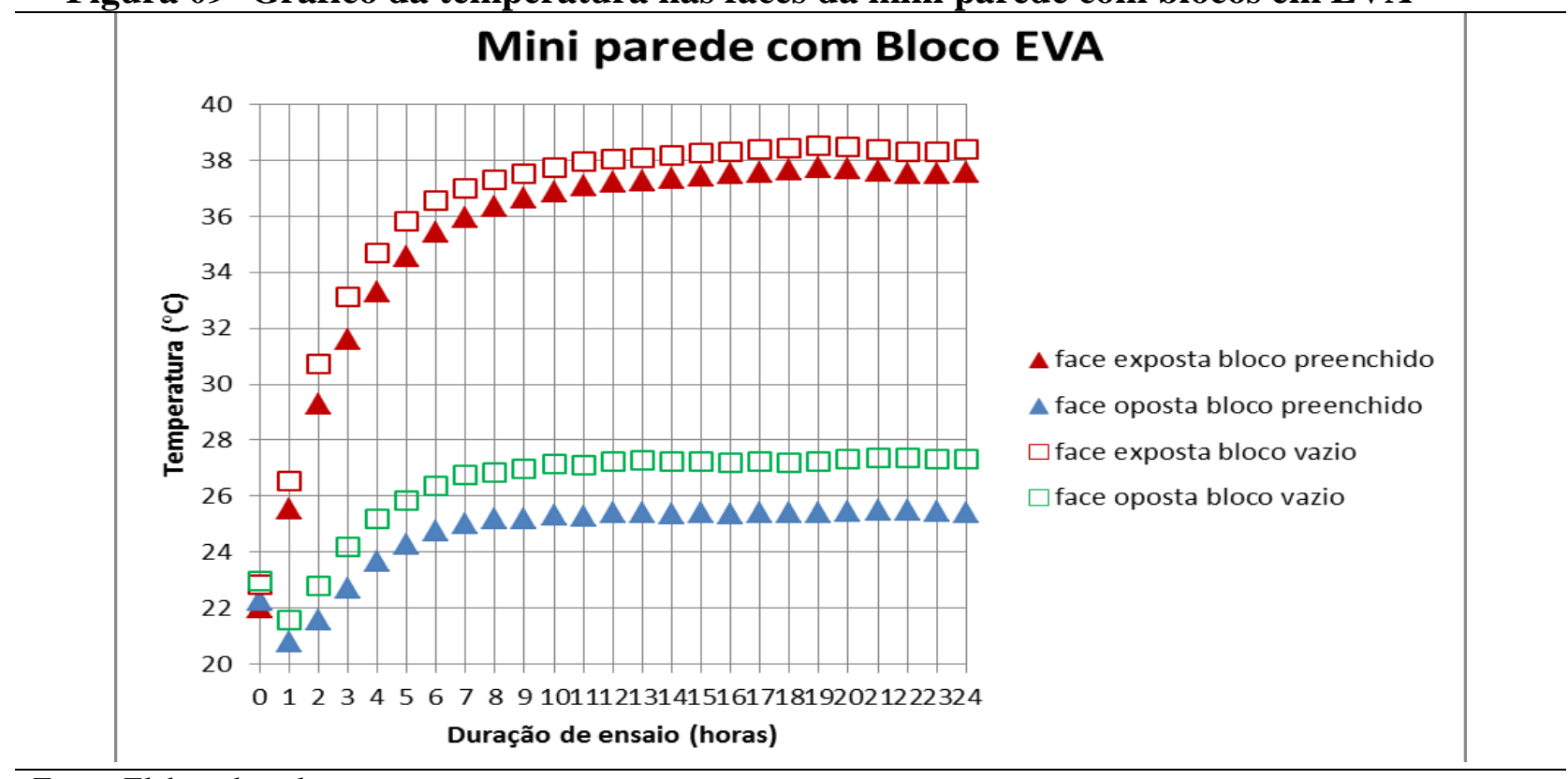

Fonte: Elaborado pelos autores 
Na face oposta ao calor, a metade com blocos EVA preenchidos apresentou menores temperaturas, no entanto, observa-se que, considerando a amplitude da diferença entre as temperaturas médias das duas metades (com blocos preenchidos e vazios) nas faces oposta e exposta ao calor, a parte com blocos vazios de EVA apresentou menor amplitude - cerca de $11^{\circ} \mathrm{C}$ contra os $12^{\circ} \mathrm{C}$ registrados na metade da amostra com blocos preenchidos-. Quanto à temperatura global (média dos termopares de cada face da mini parede, desprezando as quatro primeiras horas iniciais) observa-se que o bloco de EVA vazio apresentou menor variação de temperatura entre a face oposta e exposta ao calor. A diferença entre as temperaturas globais foi de apenas $1^{\circ} \mathrm{C}$ (Tabela 01 ).

Tabela 01- Temperatura global da mini parede com bloco EVA

\begin{tabular}{|cccc|}
\hline \multicolumn{4}{|c|}{ TEMPERATURA GLOBAL NA MINI PAREDE COM BLOCOS EVA } \\
\hline Bloco & $\begin{array}{c}\text { Face aquecida } \\
\left({ }^{\circ} \mathbf{C}\right)\end{array}$ & $\begin{array}{c}\text { Face } \\
\text { refrigerada }\left({ }^{\circ} \mathbf{C}\right)\end{array}$ & $\begin{array}{c}\text { Variação de temperatura entre a } \\
\text { face aquecida e refrigerada }\left({ }^{\circ} \mathbf{C}\right)\end{array}$ \\
\hline Bloco preenchido & 37,6 & 25,4 & 12,1 \\
\hline Bloco vazio & 38,4 & 27,3 & 11,1 \\
\hline $\begin{array}{c}\text { Variação entre bloco } \\
\text { vazio e preenchido }\end{array}$ & 0,8 & 1,9 & 1,0 \\
\hline
\end{tabular}

Fonte: Elaborado pelos autores

\section{Etapa II- Desempenho térmico da mini parede com blocos de concreto}

A figura 10 mostra as temperaturas coletadas durante as 24 horas de ensaio na mini parede com blocos de concreto preenchidos e vazios. Pode-se observar que, tanto na face exposta à fonte de calor $\left(\sim 38^{\circ} \mathrm{C}\right)$ quanto na face oposta $\left(\sim 28^{\circ} \mathrm{C}\right)$ as duas partes da mini-parede (com blocos preenchidos e blocos vazios) apresentaram desempenho semelhante.

Figura 10- Gráfico da temperatura nas faces das mini paredes com bloco de concreto

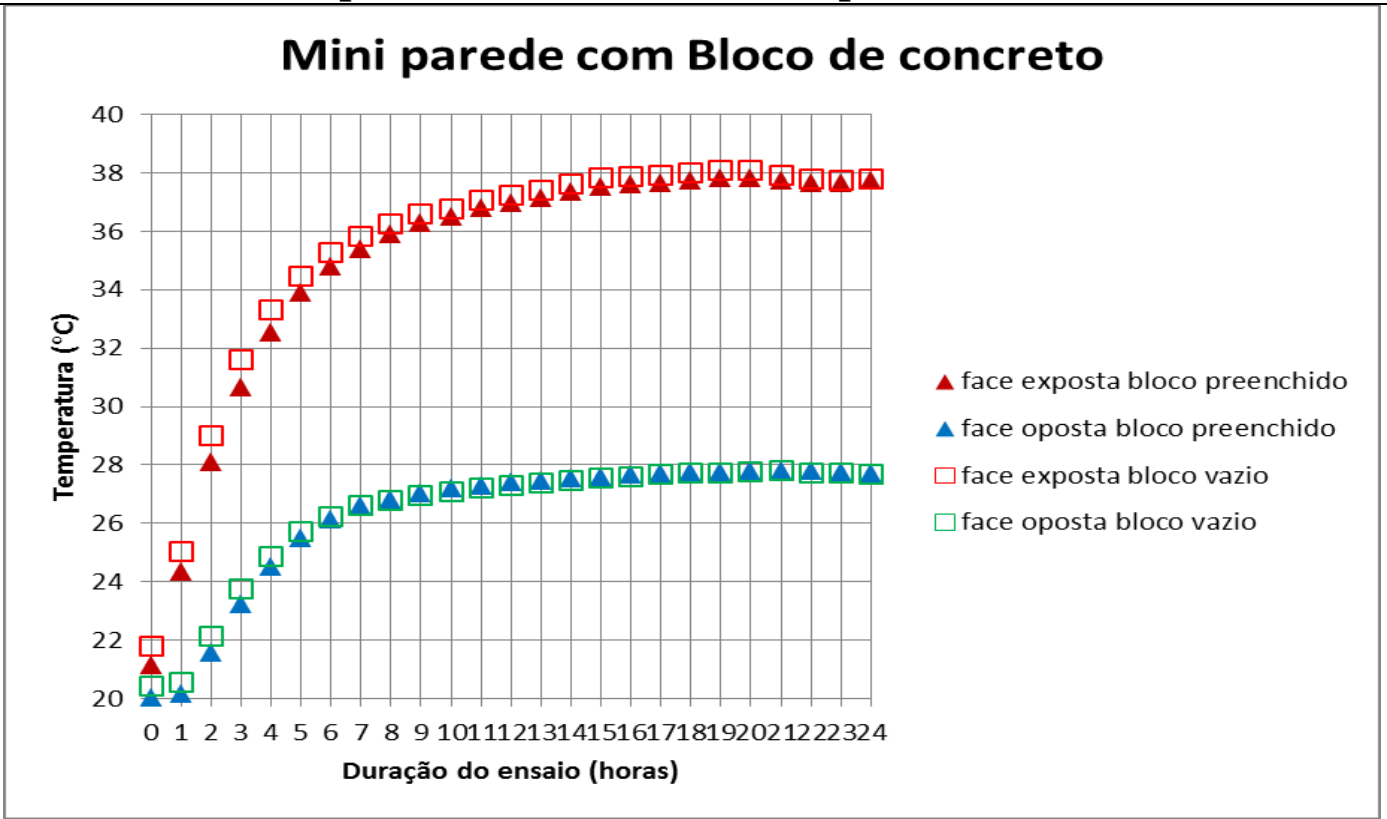

Fonte: Elaborado pelos autores

Os valores encontrados nas médias das temperaturas dos termopares utilizados mostra uma diferença de apenas $0,2^{\circ} \mathrm{C}$ entre as metades com blocos de concreto preenchidos e vazios. Os resultados indicam que, no caso da mini parede com blocos de concreto, o fato de o 
bloco ser preenchido ou vazado não apresentou diferença significativa na redução da variação de temperatura (Tabela 02).

Tabela 02- Temperatura global da mini parede com bloco de concreto

\begin{tabular}{|cccc|}
\hline \multicolumn{4}{|c|}{ TEMPERATURA GLOBAL NA MINI PAREDE COM BLOCOS DE CONCRETO } \\
\hline Bloco & $\begin{array}{c}\text { Face } \\
\text { aquecida }\left({ }^{\circ} \mathbf{C}\right)\end{array}$ & $\begin{array}{c}\text { Face refrigerada } \\
\left({ }^{\circ} \mathbf{C}\right)\end{array}$ & $\begin{array}{c}\text { Variação de temperatura entre a } \\
\text { face aquecida e refrigerada }\left({ }^{\circ} \mathbf{C}\right)\end{array}$ \\
\hline Bloco preenchido & 37,7 & 27,7 & 10.0 \\
\hline Bloco vazio & 37,9 & 27,7 & 10.2 \\
\hline $\begin{array}{c}\text { Variação entre bloco } \\
\text { vazio e preenchido }\end{array}$ & 0.2 & 0 & 0.2 \\
\hline
\end{tabular}

Fonte: Elaborado pelos autores

\section{Etapa III- Comparação do desempenho térmico das mini paredes de EVA e de Concreto}

Os resultados obtidos com a mini parede de blocos EVA indicam que o bloco preenchido apresenta desempenho térmico ligeiramente melhor que o bloco vazado. Com relação à diferença entre os blocos de EVA e de concreto, acredita-se que o agregado de EVA presente na composição do bloco tenha contribuído para melhorar o isolamento térmico. Nas temperaturas médias globais (Figura 11), pode-se observar que a diferença de temperatura entre a parte da amostra com blocos de EVA vazios apresentou melhor desempenho térmico que a de blocos de concreto vazios e preenchidos. Já a amostra com blocos EVA preenchidos, teve melhor capacidade de isolamento que a amostra com blocos de concreto preenchidos e também do que a amostra de blocos de concreto vazios.

\section{Figura 11- Temperaturas médias globais $\left({ }^{\circ} \mathrm{C}\right)$ e suas variações para cada termopar}

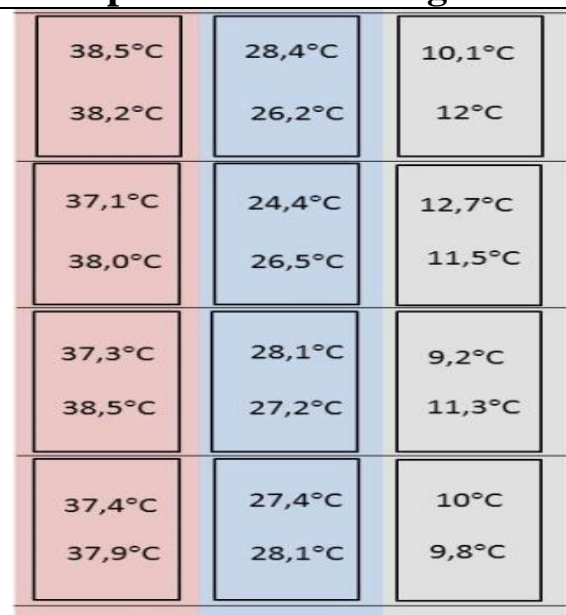

Face exposta Face oposta Média das ao calor

\section{Amostra}

bloco EVA vazio

Média da variação $=11,1^{\circ} \mathrm{C}$

Amostra

bloco EVA preenchido

Média da variação $=12,1^{\circ} \mathrm{C}$

Amostra

bloco de concreto vazio

Média da variação $=10,2^{\circ} \mathrm{C}$

Amostra

bloco de concreto preenchido

Média da variação $=10^{\circ} \mathrm{C}$

Fonte: Elaborado pelos autores

A diferença das variações de temperatura entre as amostras de blocos de EVA preenchidos e de blocos de concreto preenchidos foi de aproximadamente $2,1^{\circ} \mathrm{C}$. O bloco de EVA preenchido teve uma variação média de $12,1^{\circ} \mathrm{C}$ e o de concreto vazio, $10^{\circ} \mathrm{C}$. Em contrapartida, a diferença entre a variação das amostras de blocos vazios (EVA e concreto) foi de $0,9^{\circ} \mathrm{C}$, onde a variação de temperatura na amostra com blocos de EVA vazios $(\sim 11,1)$ foi maior que a com bloco de concreto vazios $(\sim 10,2)$, caracterizando um melhor isolamento da amostra com os blocos EVA. A face oposta ao calor da amostra com blocos EVA preenchidos permaneceu durante todo o ensaio com temperaturas mais amenas que a dos blocos EVA vazios. Enquanto isso na face exposta ao calor das amostras de com blocos EVA, os blocos vazios e preenchidos permaneceram com as temperaturas bem próximas. 
Quanto as mini parede de concreto, as temperaturas foram muito próximas no decorrer das 24horas de ensaio, tanto na face exposta ao calor quanto na oposta (Figura 12).

Figura 12- Gráfico do comportamento térmico das mini paredes

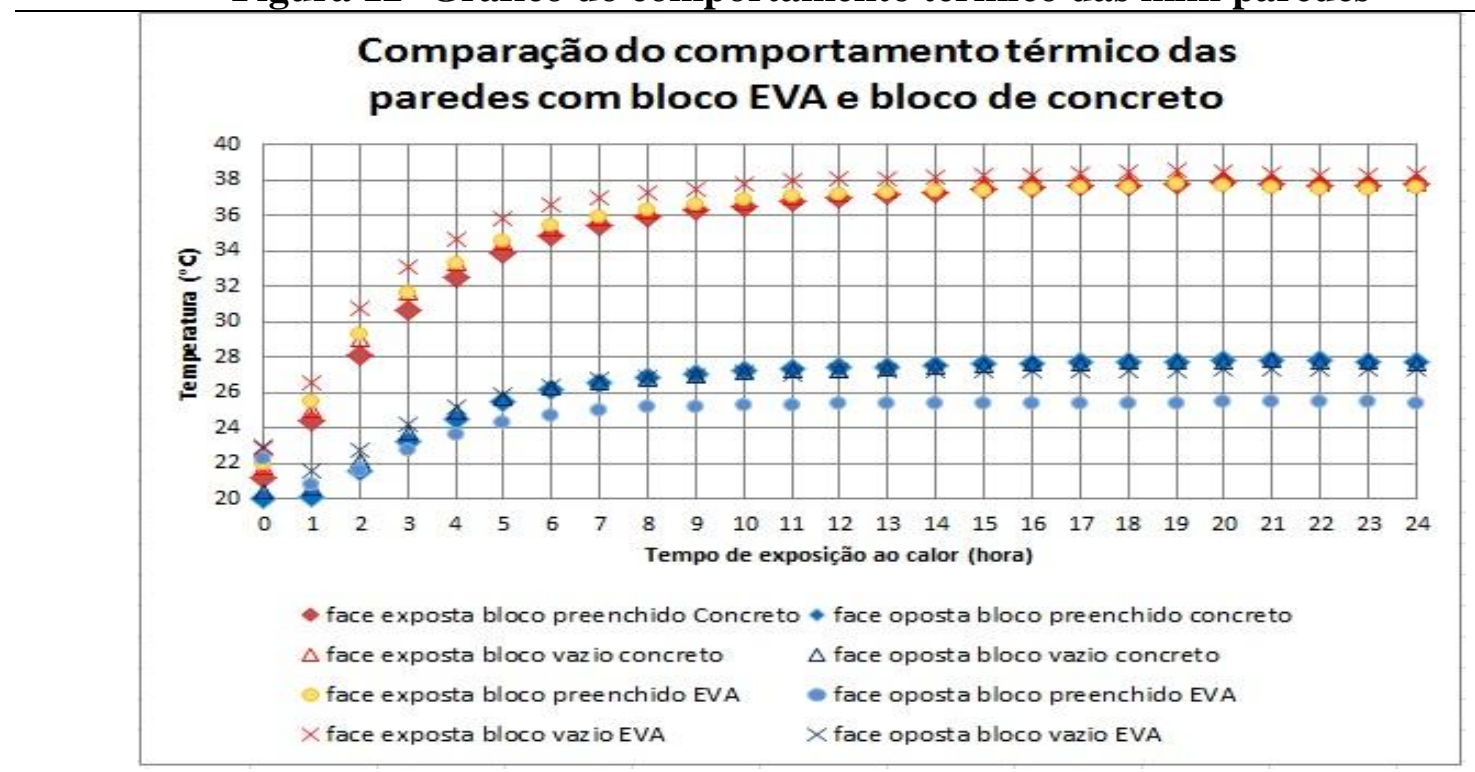

Fonte: Elaborado pelos autores

Nos cálculos de desempenho térmico segundo a norma de desempenho, foram encontrados os valores da resistência térmica, transmitância térmica, capacidade térmica e atraso térmico dos blocos de concreto e dos blocos EVA (vazios e preenchidos). Através de dados da condutividade térmica, densidade, calor específicos dos materiais. Os cálculos foram desenvolvidos, tendo como base a norma 15220-2 (ABNT,2005a) e os valores encontrados podem ser observados na Tabela 03 .

Tabela 03 - Valores encontrados nos cálculos de desempenho térmico das mini paredes

\begin{tabular}{ccccc}
\hline $\begin{array}{c}\text { Fatores de desempenho } \\
\text { térmico }\end{array}$ & $\begin{array}{c}\text { bloco EVA } \\
\text { preenchido }\end{array}$ & $\begin{array}{c}\text { bloco EVA } \\
\text { vazio }\end{array}$ & $\begin{array}{c}\text { bloco de concreto } \\
\text { preenchido }\end{array}$ & $\begin{array}{c}\text { bloco de } \\
\text { concreto vazio }\end{array}$ \\
\hline $\begin{array}{c}\text { Resistência térmica }-\mathrm{R}_{\mathrm{t}} \\
\left(\mathrm{m}^{2} . \mathrm{K}\right) / \mathrm{W}\end{array}$ & 0,1385 & 0,1961 & 0,0527 & 0,1059 \\
\hline $\begin{array}{c}\text { Resistência térmica total- } \mathrm{R}_{\mathrm{T}} \\
\left(\mathrm{m}^{2} . \mathrm{K}\right) / \mathrm{W}\end{array}$ & 0,3086 & 0,3661 & 0,2227 & 0,2759 \\
\hline $\begin{array}{c}\text { Transmitância térmica- U } \\
\mathrm{W} /\left(\mathrm{m}^{2} \cdot \mathrm{K}\right)\end{array}$ & 3,3 & 2,7 & 4,5 & 3,6 \\
\hline $\begin{array}{c}\text { Capacidade térmica- C } \\
\mathrm{KJ} /\left(\mathrm{m}^{2} \cdot \mathrm{K}\right)\end{array}$ & 171,3 & 90,2 & 204,3 & 109,2 \\
\hline $\begin{array}{c}\text { Atraso Térmico- } \varphi \\
\text { horas }\end{array}$ & 2,82 & 2,10 & 1,89 & 1,93 \\
\hline
\end{tabular}

Fonte: Elaborado pelos autores

O bloco que apresentou a maior resistência térmica e melhores resultados de transmitância térmica foi o de EVA vazio, o que pode ser justificado pela presença de câmara de ar no bloco e pela porosidade do material. Com isso o bloco de EVA vazio e preenchido fornecem melhor isolamento que os de concreto. O bloco que apresentou pior desempenho no quesito resistência térmica (Rt), foi o de concreto preenchido. Conforme Figueira (2005), uma capacidade térmica elevada não garante por si só uma melhor regulação térmica na construção. Na capacidade térmica é levada em consideração a espessura dos materiais, sua densidade e calor específico (ABNT, 2005a). Como a densidade dos blocos preenchidos e vazios foram as mesmas (EVA $\rho=1900 \mathrm{Kg} \cdot \mathrm{m}^{3}$; Concreto $\rho=2300 \mathrm{Kg} \cdot \mathrm{m}^{3}$ ), o 
ideal para julgar o desempenho é levar em consideração a condutividade térmica ( $\lambda$ ). O que torna os blocos com EVA piores condutores de calor (EVA $\lambda=0,61 \mathrm{~W} / \mathrm{m} . \mathrm{K}$; Concreto $\lambda=1,7561 \mathrm{~W} / \mathrm{m} . \mathrm{K})$. Dentre os blocos analisados o que apresentou o maior atraso térmico $(\varphi)$ foi o de EVA preenchido, tendo o valor de 2,82 horas, seguido pelo bloco de EVA vazio com 2,10 horas. Os blocos de concreto vazios apresentaram o menor atraso térmico.

\section{CONSIDERAÇÕES FINAIS}

Com os resultados desta pesquisa, acredita-se que os blocos com adição de EVA apresentam implicações eficientes no isolamento térmico. Percebeu-se também a necessidade de pesquisas que informem valores consolidados de calor específico e densidade do bloco EVA, visto que não há valores estabelecidos para cálculos de desempenho térmico na norma 15220-2 (ABNT, 2005a), o que dificulta resultados mais precisos de desempenho térmico. Neste estudo afirma-se que a amostra de mini parede composta por blocos EVA preenchidos obteve melhor desempenho térmico que as demais avaliadas. A ausência de porosidade dos blocos de concreto preenchidos provavelmente influenciou na obtenção do pior desempenho térmico. Nas amostras de concreto verificouse que a presença da câmara de ar não contribuiu para uma diminuição considerável na temperatura. Finalmente, confirmou-se o melhor desempenho das duas amostras de EVA (blocos vazios e preenchidos) sobre as amostras de concreto simples. Esse estudo contribui para estimular a utilização do EVA na produção de blocos de vedação na construção civil.

\section{RFFERÊNCIAS}

ANDRADE, L. A. S.; MEDEIROS R. Reaproveitamento de rejeitos de E.V.A. para a produção de placas utilizáveis na construção civil. Linkania Master. Ano 2 - No 03 - Abril/Julho de 2012. ASSOCIAÇÃO BRASILEIRA DE NORMAS TÉCNICAS (ABNT). NBR 15220-2: Desempenho Térmico das Edificações. Parte 2: Método de cálculo da transmitância térmica, da capacidade térmica, do atraso térmico e do fator solar de elementos e componentes construtivos. Rio de Janeiro, 2005a.

ASSOCIAÇÃO BRASILEIRA DE NORMAS TECNICAS (ABNT). NBR 15220-3: Desempenho termico de edificações - parte 3: zoneamento bioclimatico brasileiro e diretrizes construtivas para habitações unifamiliares de interesse social. Rio de Janeiro, 2005b.

ASSOCIAÇÃ̃O BRASILEIRA DE NORMAS TÉCNICAS (ABNT). NBR NM 248: AgregadosDeterminação da composição granulométrica. Rio de Janeiro, 2003.

FIGUEIRA, D.S. Análise experimental e numérica do comportamento térmico de um coletor solar acumulador. Tese (Doutorado em Engenharia) Escola de Engenharia. Universidade Federal do rio Grande do Sul. Porto Alegre, 2005.

FILHO, R. S. P. Contribuição ao processo de reciclagem dos resíduos sólidos da indústria de calçados na construção civil: bloco EVA - uma alternativa às alvenarias das construções. Dissertação de mestrado. Programa de Pós-graduação em Engenharia Urbana. João Pessoa, 2005. GARLET, G.; GREVEN, H. A. Concreto leve usando resíduos de EVA da indústria calçadista. I Encontro Nacional Sobre Edificações e Comunidades Sustentáveis. Canela/RS, 1997.

MELO, A. B.; FILHO, M. R. F. L. Avaliação de desempenho estrutural de protótipo com paredes construídas com blocos EVA. Ambiente Construído, Porto Alegre, v. 9, n. 4, p. 141-155, out./dez. 2009.

ROCHA, J. C.; CHERIAF, M. Coletânea Habitare vol. 4. ANTAC. Porto Alegre, 2003. SILVA, E. P.; CAHINO J. E. M.; MELO A. B. Avaliação de desempenho térmico de blocos EVA. ENTAC, Juiz de fora. 2012. 